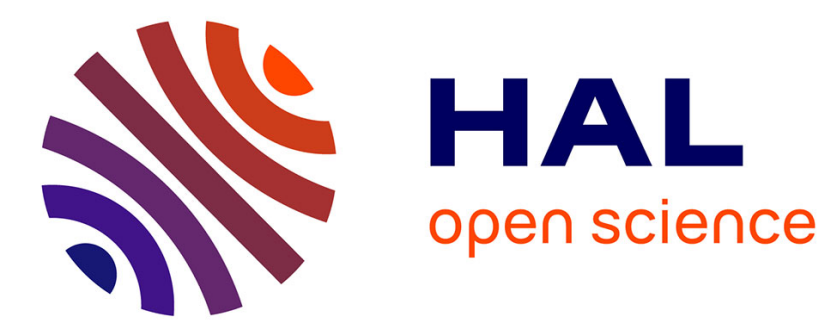

\title{
Dynamic Molecular Metamorphism involving Palladium-Assisted Dimerization of $\pi$-Cation Radicals
}

Christophe Kahlfuss, Raymond Grüber, Elise Dumont, Guy Royal, Floris Chevallier, Eric Saint-Aman, Christophe Bucher

\section{- To cite this version:}

Christophe Kahlfuss, Raymond Grüber, Elise Dumont, Guy Royal, Floris Chevallier, et al.. Dynamic Molecular Metamorphism involving Palladium-Assisted Dimerization of $\pi$-Cation Radicals. Chemistry - A European Journal, 2018, 10.1002/chem.201805017 . hal-01927373

\section{HAL Id: hal-01927373 https://hal.science/hal-01927373}

Submitted on 1 Dec 2020

HAL is a multi-disciplinary open access archive for the deposit and dissemination of scientific research documents, whether they are published or not. The documents may come from teaching and research institutions in France or abroad, or from public or private research centers.
L'archive ouverte pluridisciplinaire HAL, est destinée au dépôt et à la diffusion de documents scientifiques de niveau recherche, publiés ou non, émanant des établissements d'enseignement et de recherche français ou étrangers, des laboratoires publics ou privés. 


\title{
Dynamic Molecular Metamorphism involving Palladium-Assisted Dimerization of $\pi$-Cation Radicals
}

\author{
Christophe Kahlfuss, ${ }^{[a]}$ Raymond Grüber, ${ }^{[a]}$ Elise Dumont, ${ }^{[a]}$ Guy Royal, ${ }^{[b]}$ Floris Chevalier, ${ }^{\text {[a] }}$ Eric Saint- \\ Aman ${ }^{\star[b]}$ and Christophe Bucher ${ }^{*[a]}$
}

\begin{abstract}
A dynamic supramolecular approach is developed to promote the $\pi$-dimerization of viologen radicals at room temperature and in standard concentration ranges. It involves cisor trans-protected palladium centers serving as inorganic hinges linking two functionalized viologens endowed with metal-ion coordinating properties. On the ground of detailed spectroscopic, electrochemical and computational data, we show that the one electron electrochemical reduction of the viologen units in different dynamic metal:ligand mixtures leads to the formation of the same intramolecular $\pi$-dimer, regardless of the initial environment around the metallic precursor and of the relative ratio between metal and ligand initially introduced in solution. The large scale electron-triggered reorganization of the building blocks introduced in solution thus involves drastic changes in the stoichiometry and stereochemistry of the palladium/viologen complexes proceeding in some cases through a palladium centered trans $\rightarrow$ cis isomerization of the coordinated ligands
\end{abstract}

\section{Introduction}

Over the course of a few decades, $\pi$-radicals have become key players in supramolecular chemistry. They have proved particularly relevant to the development of organic molecular conductors and magnet materials or to provide access to molecular hosts displaying switchable recognition/transport properties. $^{1-6}$ Most of these achievements in very different application areas involve stable electron-deficient or electron-rich $\pi$-radicals used as building blocks for the construction of molecular or supramolecular complexes stabilized by charge transfer processes. ${ }^{7-10}$ Another salient, albeit far less exploited, feature of $\pi$-radicals is their ability to form cofacial diamagnetic complexes, commonly known as $\pi$-dimers. Many previous studies have revealed that such bimolecular assembly can potentially be formed by association of two anionic, cationic and even neutral radicals held together within cofacial structures featuring sub van der Waals interplanar distances. ${ }^{5,11-14}$

Viologen derivatives are unique among the many $\pi$-conjugated systems capable of forming $\pi$-dimers ${ }^{11}, 14,15$ in that their association at the ground state (dicationic non radical state) is

[a] Dr. C. Kahlfuss, Dr. R. Grüber, Prof. E. Dumont, Dr. C. Bucher Laboratoire de Chimie UMR 5182, CNRS - Univ Lyon, ENS de Lyon,

Université Claude Bernard Lyon 1, F69342, Lyon, France

E-mail: christophe.bucher@ens-lyon.fr

[b] Prof. G. Royal, Dr. S. Cobo, Prof. E. Saint-Aman Université Grenoble-Alpes, CNRS, Département de Chimie Moléculaire (UMR 5250), F38400 Grenoble. France.

E-mail: eric.saint-aman@univ-grenoble-alpes.fr

Supporting information for this article is given via a link at the end of the document. prevented by repulsive electrostatic forces. Such an advantageous feature does not apply for instance to neutral or weakly charged polyaromatics forming cofacial dimeric complexes both in their ground states (stabilized by so called " $\pi$ $\pi$ " interactions) and in their radical states (stabilized by pimerization or by $\pi$-dimerization). The dimerization of viologen radicals has been shown over the years to be a fully reversible process proceeding with fast kinetics and to be readily identified by standard spectroscopic and electrochemical techniques. ${ }^{16,17}$ Despite all these positive features, the use of $\pi$-dimers in supramolecular chemistry has been so far greatly limited by experimental issues mostly arising from their quite weak formation constants, the latter being eventually circumvented in confined environment, in dendrimeric structures, ${ }^{18,}{ }^{19}$ or in non standard conditions involving either large concentrations of radicals or low temperatures. ${ }^{20-24}$

One strategy that we have used over the past few years to circumvent these issues and to promote the formation of intramolecular $\pi$-dimers between viologen cation radicals relies on tedious multi-steps sequences aiming at introducing suitable organic covalent linkers between both $\pi$-units involved in the dimerization (Scheme 1A). ${ }^{25-36}$ Works carried out along these lines have led to the emergence of a wide range of responsive metamorphic molecular systems whose conformation can be controlled by redox input. ${ }^{5,10,12-15,20,23,37-41}$

We now wish to report a far more straightforward and effective approach where preorganization of the redox-active tectons and their $\pi$-dimerization are promoted by implementation of selfassembly principles. The basic concepts underlying this novel approach are illustrated in Scheme 1B with simple sketches.

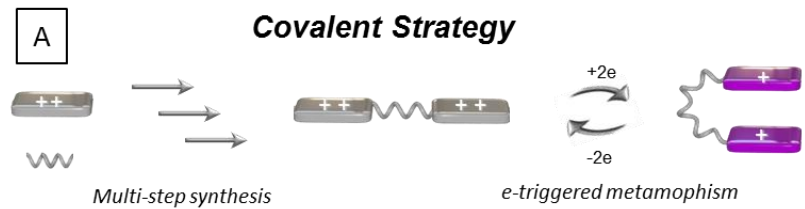

B Dynamic Supramolecular Strategy

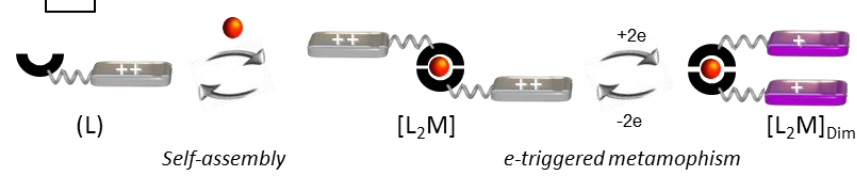

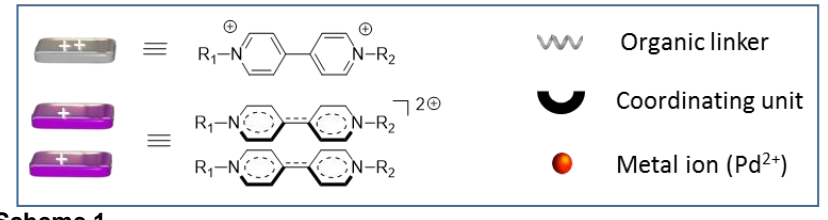

Scheme 1. 
The idea was to provide each viologen with the ability to spontaneously self-assemble in the presence of metal ions through their functionalization with suitable coordinating groups. As part of this strategy, it was anticipated that the number and relative position of viologen-appended ligands ( $L$ on Scheme 1 ) assembled around each metal center could be controlled by a careful design of the coordinating unit (denticity, topicity, structure...) together with a thoughtful selection of the metal center (coordination number, geometry...).

In the present study, a palladium (II) ion has been used as an inorganic hinge allowing to bring together two imidazole appended viologens and to promote the intramolecular dimerization of the electrogenerated $\pi$-cation radical. Pd (II) has been selected i) for its ability to form well-defined and thermodynamically stable square planar complexes featuring either cis-protected, trans-protected or unprotected $\mathrm{Pd}^{2+}$ ions, ii) for the labile nature of the $\mathrm{Pd}$-nitrogen bond providing a dynamic character to the targeted self-assembly processes, as well as iii) for the chemical inertness and redox inactivity of most palladium complexes over large potential windows. ${ }^{42}$ In the following paragraphs, the $\mathrm{Pd}$-assisted $\pi$-dimerization processes involving a rigid and linear viologen-imidazole conjugate will be discussed based on spectroscopic and (spectro-) electrochemical and computational data.

\section{Results and Discussion}

The structure and the synthesis of the targeted tecton $4\left(\mathrm{PF}_{6}\right)_{2}$, featuring an electro-active viologen and an imidazole ligand as key functional elements, ${ }^{29}$ are shown in Figure 1. A conjugated butadiynyl spacer was selected to minimize steric hindrance and to provide a relative flexibility to the tecton. The Key intermediate 3 was obtained from a modified Cadiot-Chodkiewicz ${ }^{43}$ coupling reaction involving 1 and 2 as reactants.

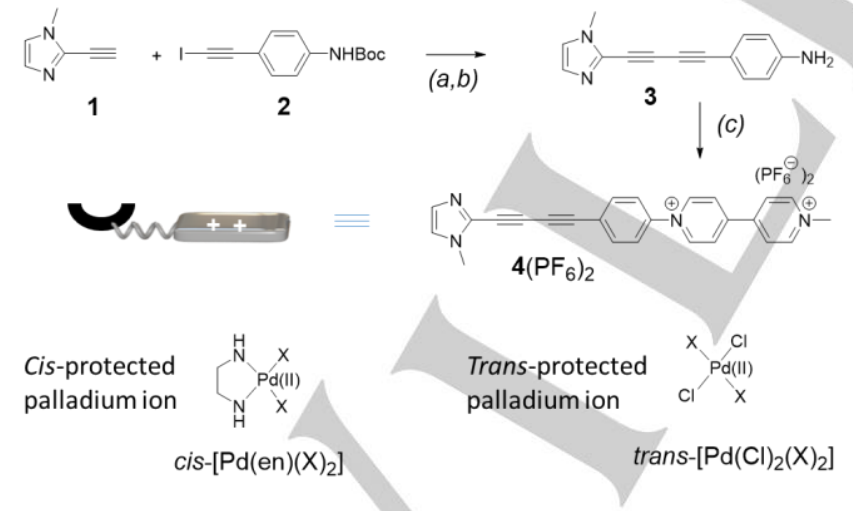

Figure 1. a) $\mathrm{Pd}\left(\mathrm{PPh}_{3}\right)_{2} \mathrm{Cl}_{2}$, Cul, $\mathrm{THF} / \mathrm{Et}_{3} \mathrm{~N}, 45^{\circ} \mathrm{C}, 30 \mathrm{~min}, 40 \%$. b) $\mathrm{CF}_{3} \mathrm{CO}_{2} \mathrm{H}$, $\mathrm{CH}_{2} \mathrm{Cl}_{2}$, r.t. 30 min, $90 \%$ \%. c) 1-(2,4-dinitrophenyl)-1'-methyl-4,4'-bipyridinium hexafluorophosphate, $\mathrm{EtOH} / \mathrm{CH}_{3} \mathrm{CN}$, reflux $18 \mathrm{~h}, 58 \%$.

The targeted compound $\mathbf{4}\left(\mathrm{PF}_{6}\right)_{2}$ was ultimately obtained from a Zincke coupling reaction ${ }^{44}$ involving the aniline appended methyl imidazole 3 and a 2,4-dinitrophenyl-substituted viologen precursor. The metal induced self-assembly has been investigated with two different palladium sources featuring either a cis- or a trans- protected coordination scheme (Figure 1), namely the cis-(ethylenediamine)dinitratopalladium(II) complex, noted cis-[ $\left.\mathrm{Pd}\left(\mathrm{NO}_{3}\right)_{2}(\mathrm{en})\right]$, and the trans-bis(acetonitrile)dichloropalladium(II) complex, noted trans- $\left[\mathrm{Pd}\left(\mathrm{Cl}_{2}\left(\mathrm{CH}_{3} \mathrm{CN}\right)_{2}\right]\right.$, wherein the exchangeable coordination sites are occupied by nitrate anions and acetonitrile molecules, respectively ( $\mathrm{X}$ in Figure 1).

\section{${ }^{1} \mathrm{H}$ NMR characterization of the palladium complexes.}

The self-assembled species formed in solution at different metal/ligand ratio could be readily identified by ${ }^{1} \mathrm{H}$ NMR measurements. Similar behaviours have been observed in deuterated DMSO and DMF (A fully attributed spectrum of $4\left(\mathrm{PF}_{6}\right)_{2}$ is provided in the supplementary section as Fig. ESI 13). The changes observed in $\mathrm{d}^{6}$-DMSO upon addition of increasing amounts of cis- $\left[\mathrm{Pd}\left(\mathrm{NO}_{3}\right)_{2}(\mathrm{en})\right]$ are shown in Figure 2 with a focus at high field on two signals at 4.45 and $3.77 \mathrm{ppm}$, attributed to the methyl substituents on the pyridine and imidazole rings, respectively.
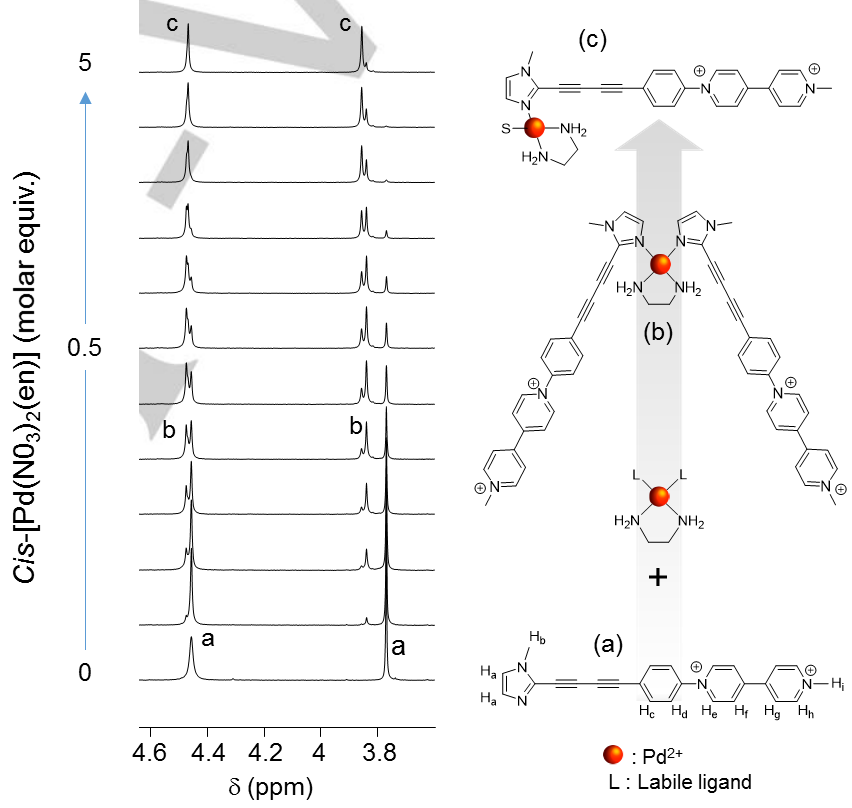

Figure 2. Partial ${ }^{1} \mathrm{H}$ NMR spectra of $4\left(\mathrm{PF}_{6}\right)_{2}\left(2 \mathrm{mM}\right.$, DMSO- $d_{6}, 500 \mathrm{MHz}$ ) recorded during the addition of cis-[ $\left.\mathrm{Pd}\left(\mathrm{NO}_{3}\right)_{2}(\mathrm{en})\right]$ (number of equivalents, $\mathrm{n}_{\text {eq }}$ $\mathrm{Pd}$, written on the left). The signal of $4^{2+}$, cis- $\left[\mathrm{Pd}^{2+}(\mathrm{en})\left(4^{2+}\right)_{2}\right]$ and cis$\left[\mathrm{Pd}^{2+}(\mathrm{en})(\mathrm{S})\left(\mathbf{4}^{2+}\right)\right]$ are labelled with $\mathrm{a}, \mathrm{b}$ and c, respectively.

The equilibria involved in solution are kinetically slow at the NMR time scale and the largest shifts of about $0.5 \mathrm{ppm}$ are observed for the signals attributed to the protons of the imidazole ring. A detailed analysis of the spectra reveals that two different complexes are formed in solution: The 1:2 complex cis$\left[\mathrm{Pd}^{2+}(\mathrm{en})\left(4^{2+}\right)_{2}\right]$, accumulating at the early stage of the titration, and the $1: 1$ species cis- $\left[\mathrm{Pd}^{2+}(\mathrm{en})\left(4^{2+}\right)(\mathrm{S})\right]$ (where $\mathrm{S}$ represents a coordinating solvent molecule), formed towards the end of the experiment. These conclusions are supported by the observation of three different sets of signals whose intensities vary over the course of the titration. For instance, the protons resonating at 3.77 $\mathrm{ppm}$ in the free ligand $4^{2+}$ gets shifted to $3.84 \mathrm{ppm}$ in cis$\left[\mathrm{Pd}^{2+}(\mathrm{en})\left(4^{2+}\right)_{2}\right]$ and to $3.85 \mathrm{ppm}$ in cis- $\left[\mathrm{Pd}^{2+}(\mathrm{en})\left(4^{2+}\right)(\mathrm{S})\right]$ (Figure $2)$. We found that the maximum concentrations in cis- 
$\left[\mathrm{Pd}^{2+}(\mathrm{en})\left(4^{2+}\right)_{2}\right]$ and $\left[\mathrm{Pd}^{2+}(\mathrm{en})\left(4^{2+}\right)(\mathrm{S})\right]$ are obtained after addition of 0.5 and 5 molar equivalents of $\mathrm{Pd}$ (II), respectively and that the relative concentration of each species do not vary over time. We then turned our attention towards assessing the conformation of the cis- $\left[\mathrm{Pd}^{2+}(\mathrm{en})\left(4^{2+}\right)_{2}\right]$ complex in solution. A preliminary analysis based on the minimization of steric and electrostatic repulsive forces led us to identify the anti-conformation shown in Figure 3 as the most favourable one. This arrangement not only sets both positively charges units far away from each other, it also enables to minimize the steric repulsion between the imidazole, ethynyl and ethylenediamine moieties. Such conclusion does not apply to the "coplanar" or "cis" arrangements also depicted in Figure 3, wherein steric or electrostatic repulsive forces reach maximum values. The assumption that both rigid viologen-containing ligands assembled around the same palladium center in cis$\left[\mathrm{Pd}^{2+}(\mathrm{en})\left(4^{2+}\right)_{2}\right]$ adopt an anti-like conformation has been further confirmed by ${ }^{1} \mathrm{H}$ NMR spectroscopy using the chemical shifts of the protons on the viologen units as probes, assuming that the proximity between $\pi$ rings can be revealed through the observation of low field shifts in the aromatic region. ${ }^{45}$ In support of the above mentioned hypothesis that both aromatic arms indeed do not "see" each other in solution, we found that the protons of the viologen units resonate at the same frequencies in cis- $\left[\mathrm{Pd}^{2+}(\mathrm{en})\left(4^{2+}\right)_{2}\right]$ and in cis- $\left[\mathrm{Pd}^{2+}(\mathrm{en})\left(\mathbf{4}^{2+}\right)(\mathrm{S})\right]$ and that the shift of the signals corresponding to the hydrogens on the phenyl ring is almost negligible $(0.05 \mathrm{ppm})$ through the whole titration experiment (see Fig. ESI 20). The relative stability of these isomers has been further investigated by computational methods. These calculations led to the finding that the steric repulsion between both imidazoles in the coplanar conformation is too large to enable its optimization and that the anti-conformation is indeed significantly more stable than the syn-conformation $(+17.2$ $\mathrm{kcal} . \mathrm{mol}^{-1}$ at the BP86/6-31G* + LANL2DZ level of theory).

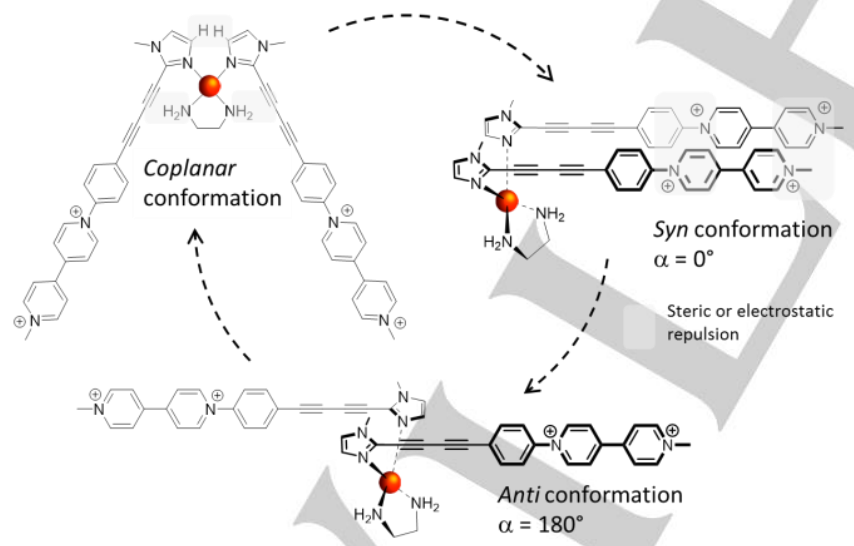

Figure 3. Representation of the syn, anti and coplanar conformations of cis$\left[\mathrm{Pd}^{2+}(\mathrm{en})\left(\mathbf{4}^{2+}\right)_{2}\right]$

A similar study was then conducted using the trans-protected complex trans- $\left[\mathrm{Pd}(\mathrm{Cl})_{2}\left(\mathrm{CH}_{3} \mathrm{CN}\right)_{2}\right]$ as the palladium source. In contrast with the previous case, different behaviours were monitored in DMSO and in DMF. Addition of increasing amounts of metal to a solution of $4^{2+}$ in $d^{6}$-DMSO led to the progressive disappearance of all the signals attributed to the free ligand at the expense of a single set of signals attributed to the $1: 1$ coordination complex trans- $\left[\mathrm{Pd}(\mathrm{Cl})_{2}(\mathrm{~S})\left(4^{2+}\right)\right]$ (see figure ESI 17 and 22). The associated NMR signals were found to reach full developments only after addition of more than 2 molar equivalents of $\mathrm{Pd}^{2+}$ and here again, the reaction time was found to be ineffective at modifying the distribution between both species involved in the complexation equilibrium. Conducting the same experiment in deuterated DMF led conversely to the observation of three consecutive species, including the expected 1:2 and 1:1 (M:L) complexes, as revealed for instance by the observation of three distinct singlets for the $\mathrm{N}$-methyl substituent of the imidazole ring (Figure 4). Failure to observe the 1:2 (M:L) complex trans$\left[\mathrm{Pd}(\mathrm{Cl})_{2}\left(4^{2+}\right)_{2}\right]$ in DMSO is still unclear. The most likely explanations are either that binding of DMSO prohibits formation of the $1: 2$ intermediate or that the $1: 1$ and $1: 2(\mathrm{M}: \mathrm{L})$ complexes cannot be distinguished by ${ }^{1} \mathrm{H}$ NMR in this solvent due to the fact the all protons fortuitously resonate at the same frequencies.

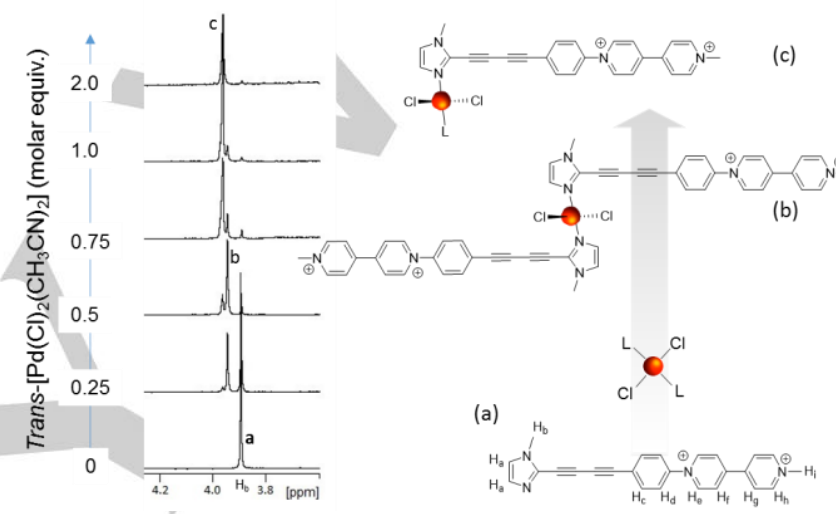

Figure 4. Partial ${ }^{1} \mathrm{H}$ NMR spectra of $4\left(\mathrm{PF}_{6}\right)_{2}\left(2 \mathrm{mM}, \mathrm{DMF}-\mathrm{d}_{7}, 500 \mathrm{MHz}\right)$ recorded during the addition of trans- $\left[\mathrm{Pd}(\mathrm{Cl})_{2}\left(\mathrm{CH}_{3} \mathrm{CN}\right)_{2}\right]$ (number of equivalents, $\mathrm{n}_{\text {eq }} \mathrm{Pd}$, written on the left). The signal corresponding to the imidazole moieties of $4^{2+}$ and trans- $\left[\mathrm{Pd}(\mathrm{Cl})_{2}\left(4^{2+}\right)_{2}\right]$ trans- $\left[\mathrm{Pd}(\mathrm{Cl})_{2}(\mathrm{~L})\left(\mathbf{4}^{2+}\right)\right]$ are labelled with $\mathrm{a}, \mathrm{b}$, and $\mathrm{c}$ respectively.

The free ligand $\mathbf{4}^{2+}$ and the associated palladium complexes have been submitted to detailed electrochemical analyses in DMF electrolytes. As expected, the voltammogram of $4^{2+}$ exhibits two consecutive and reversible viologen-based one-electron reduction waves (Fig. ESI 27) observed at $E_{1 / 2}{ }^{1}=-0.652 \mathrm{mV}\left(\Delta E_{\mathrm{p}}{ }^{1}\right.$ $\left.=60 \mathrm{mV}, \mathrm{v}=0.1 \mathrm{~V} \mathrm{~s}^{-1}\right)$ and $E_{1 / 2}{ }^{2}=-0.946 \mathrm{mV}\left(\Delta E_{\mathrm{p}}^{2}=58 \mathrm{mV}, \mathrm{v}=\right.$ $\left.0.1 \mathrm{~V} \mathrm{~s}^{-1}\right)$

These preliminary investigations have then been completed upon studying the influence of palladium on the electrochemical signature of $\mathbf{4}^{2+}$. CV curves recorded on the whole accessible potential window are provided in the ESI section but the following discussion will only focus on the first viologen-centered reduction wave. Addition of increasing amounts of cis- $\left[\mathrm{Pd}\left(\mathrm{NO}_{3}\right)_{2}\right.$ (en)], up to 0.5 molar equivalent, to a solution of $4^{2+}$ in DMF was found to induce the progressive disappearance of the initial wave attributed to the $4^{2+} / \mathbf{4}^{+\cdot}$ couple $\left(E_{1 / 2}{ }^{1}=-0.652 \mathrm{mV}, \Delta E_{\mathrm{p}}{ }^{1}=60 \mathrm{mV}\right.$, $v=0.1 \mathrm{~V} \mathrm{~s}^{-1}$, bold line in Figure 5) at the expense of a new reversible wave growing at less negative potential values $\left(E_{1 / 2}{ }^{1}=\right.$ $-0.595 \mathrm{~V}, \Delta E_{\mathrm{p}}{ }^{1}=38 \mathrm{mV}, v=0.1 \mathrm{~V} \mathrm{~s}^{-1}$ ) (thin line in Figure $5 \mathrm{~A}$ ). Further addition of palladium, from 0.5 to 3 molar equivalents, led to a second set of changes leading in fine to the development of a new wave featuring a marked irreversible character (dashed line in Figure 5A). An interesting finding that emerged from a simple analysis of the curves overlaid in Figure 5 is that the reduction of 
the complex formed after addition of an excess of palladium and that of the free ligand $4^{2+}$ occurs at the same potential values (dashed and full bolded lines in Figure $5 \mathrm{~A}$ ) whereas its back reoxidation potential matches that measured for the complex formed after addition of 0.5 molar equivalent of cis-[ $\left.\mathrm{Pd}\left(\mathrm{NO}_{3}\right)_{2}(\mathrm{en})\right]$ (dashed and full thin lines in Figure 5A).

The influence of the metal/ligand stoichiometric ratio on the electrochemical data discussed above can be readily explained by the mechanism summarized in Figure 6 involving a series of chemical $(\mathrm{C})$ and electrochemical steps $(\mathrm{E})$. The starting point for understanding the CV curve shown as a thin solid line in Figure $5 \mathrm{~A}$ is the information provided by NMR that cis- $\left[\mathrm{Pd}^{2+}(\mathrm{en})\left(4^{2+}\right)_{2}\right]$ is the main product ( $80 \%$ ) of the mixture obtained after addition of 0.5 molar equivalent of palladium.
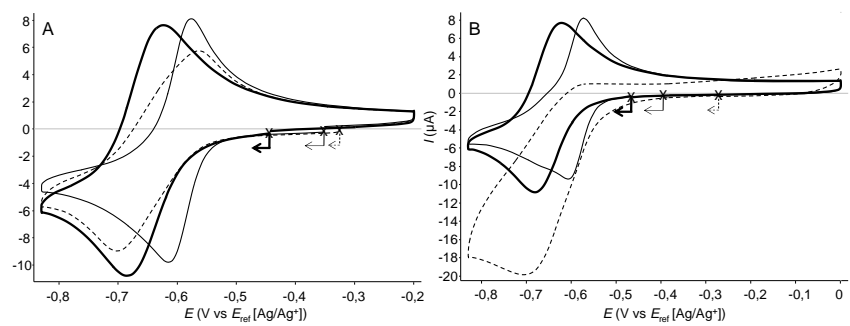

Figure 5. Raw voltametric curves measured for $4\left(\mathrm{PF}_{6}\right)_{2}$ at $0.4 \mathrm{mM}$ in $\mathrm{DMF}+$ TBAP $0.1 \mathrm{M}\left(\mathrm{VC}, \varnothing=3 \mathrm{~mm}, E(\mathrm{~V}) v s \mathrm{Ag} / \mathrm{Ag}^{+} 10^{-2} \mathrm{M}, v=0.1 \mathrm{~V} \mathrm{~s}^{-1}\right.$ ) before addition of $\mathrm{Pd}$ (II) (bold solid line), and after addition of 0.5 molar equivalent (thin solid line) of A) cis- $\left[\mathrm{Pd}\left(\mathrm{NO}_{3}\right)_{2}\right.$ (en)] and $\mathrm{B}$ ) trans-[ $\left.\mathrm{Pd}(\mathrm{Cl})_{2}\left(\mathrm{CH}_{3} \mathrm{CN}\right)_{2}\right]$, and after addition of A) 3 molar equivalents of cis-[ $\left.\mathrm{Pd}\left(\mathrm{NO}_{3}\right)_{2}(\mathrm{en})\right]$ and $\left.\mathrm{B}\right) 2$ molar equivalents of trans- $\left[\mathrm{Pd}(\mathrm{Cl})_{2}\left(\mathrm{CH}_{3} \mathrm{CN}\right)_{2}\right]$ (dashed line).

The existence of a palladium-assisted intramolecular $\pi$ dimerization coupled to the electron transfer leading in fine to the intramolecular dimer cis- $\left[\mathrm{Pd}^{2+}(\mathrm{en})_{2}\left(\mathbf{4}^{+}\right)_{2}\right]_{\mathrm{Dim}}$ (bottom of Figure 6 ), is then revealed by a careful analysis of the electrochemical curves. The most relevant data supporting this conclusion being i) a significant shift of the reduction potential towards less negative values, from $E_{1 / 2}=-0.65 \mathrm{~V}$ for the free ligand to $E_{1 / 2}=-0.59 \mathrm{~V}$, which is in agreement with a large stabilization of the electrogenerated radicals upon dimerization, ii) a drop of the $\Delta E_{\mathrm{p}}$ value from $60 \mathrm{mV}$ measured on the curve of the free ligand to 40 $\mathrm{mV}$ measured in the presence of 0.5 molar equivalent of palladium and iii) the inability of the free ligand to dimerize in the same conditions, in palladium free solutions. These electrochemical data thus support the notion that reducing the viologen units actuates a rotation of the rigid viologen-imidazole conjugates to yield the intramolecular $\pi$-dimer cis$\left[\mathrm{Pd}^{2+}(\mathrm{en})\left(\mathbf{4}^{+}\right)_{2}\right]_{\mathrm{Dim}}$ (Bottom of Figure 6). The electrochemical signature recorded at this metal/ligand ratio thus demonstrates that the main reaction pathway taken by the initial mixture submitted to an electrochemical stimulus follows the $E_{2} C$ mechanism shown as a dotted-dashed arrow in Figure 6. The first electrochemical steps are the two successive reductions of the complex cis- $\left[\mathrm{Pd}^{2+}(\mathrm{en})\left(4^{2+}\right)_{2}\right]\left(E^{\circ}{ }_{1 b} \text { and } E^{\circ}{ }_{2 b} \text { with }\left|E^{\circ}{ }_{2 b}\right|>\left|E^{\circ}{ }_{1 b}\right|\right)^{46}$ leading to the doubly reduced species $c i s-\left[\mathrm{Pd}^{2+}(\mathrm{en})\left(\mathbf{4}^{+\cdot}\right)_{2}\right]$ which is readily converted into the intramolecular dimer cis$\left[\mathrm{Pd}^{2+}(\mathrm{en})\left(\mathbf{4}^{+}\right)\right]_{\text {Dim. }}$. The stabilization of both cation radicals upon dimerization thus appears as the real driving force displacing all the equilibria involved in the initial mixture containing $4^{2+}$ (free ligand), $\quad c i s-\left[\mathrm{Pd}^{2+}(\mathrm{en})\left(4^{2+}\right)_{2}\right] \quad(1: 2 \quad$ complex $) \quad$ and $c i s-$ $\left[\mathrm{Pd}^{2+}(\right.$ en $\left.)(\mathrm{S})\left(4^{2+}\right)\right](1: 1$ complex $)$.

A similar $E_{n} C_{n}$ mechanism can be put forward to explain the shape of the CV curve recorded after addition of palladium in excess (dashed line in Figure 5A). From the NMR data discussed above, we know that the main species ( $>70 \%$, Figure ESI 21 ) in solution in these conditions is the $1: 1$ complex cis- $\left[\mathrm{Pd}^{2+}(\mathrm{en})(\mathrm{S})\left(4^{2+}\right)\right]$. From an electrochemical point of view, accumulation of this species in solution results in a large cathodic shift of the reduction potential, up to $E_{\mathrm{pc}}=-0.69 \mathrm{~V}$ matching that measured for the free ligand $4^{2+}$ $\left(E_{p c}=-0.68 \mathrm{~V}\right)$. On the other hand, the re-oxidation wave observed during the backward scan is found to be shifted to a potential $E_{\mathrm{pa}}=-0.56 \mathrm{~V}$ matching that corresponding to the reoxidation of the intramolecular dimer cis- $\left[\mathrm{Pd}^{2+}(\mathrm{en})\left(\mathbf{4}^{+}\right)\right]_{\mathrm{Dim}}\left(E_{\mathrm{pa}}=-\right.$ $0.57 \mathrm{~V})$ (Figure 5A). These findings are thus consistent with the reaction pathways shown as dashed arrows in Figure 6. The initial step is the reduction of the viologen unit in the main species cis$\left[\mathrm{Pd}^{2+}(\mathrm{en})(\mathrm{S})\left(4^{2+}\right)\right]$. Its reduction potential matches that of the free ligand $\mathbf{4}^{2+}$ because the palladium ion bound to the imidazole is just too far away from the viologen to significantly affect its electronacceptor properties.

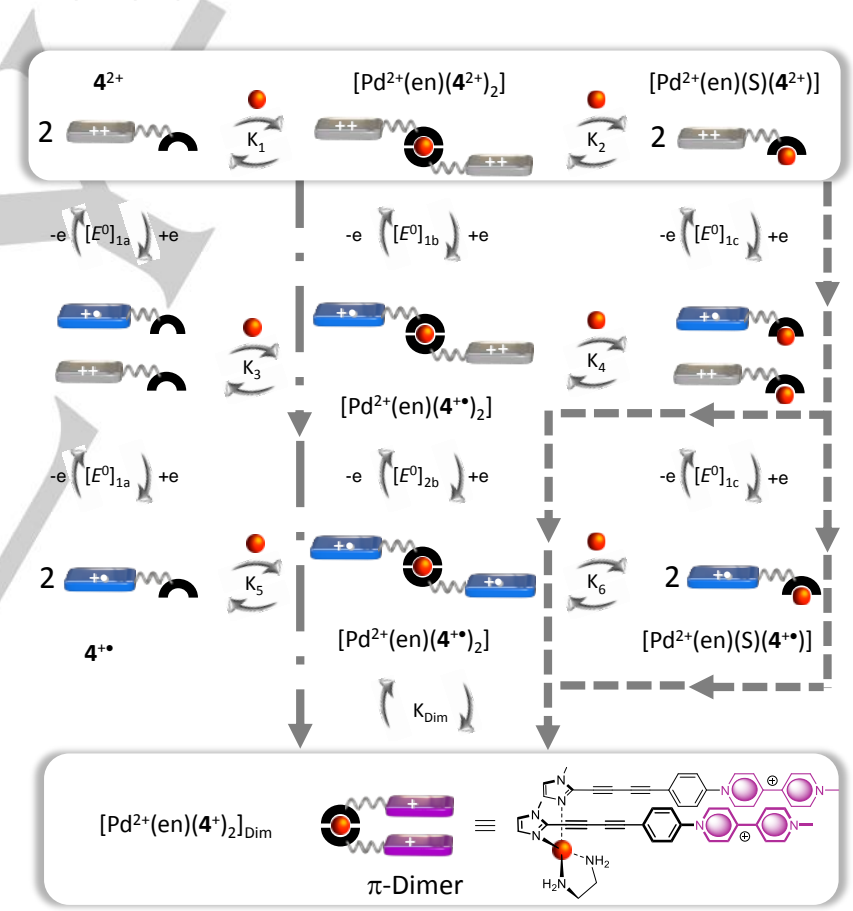

Figure 6. Schematic representation of the chemical and electrochemical reactions and equilibria involving $4^{2+}$ and of cis-[Pd(NO$\left.)_{2}(e n)\right]$. Each Electrochemical steps $(\mathrm{E})$ represented in this mecanism are mono-electronic

The electrogenerated cis-[ $\left.\mathrm{Pd}^{2+}(\mathrm{en})(\mathrm{S})\left(\mathbf{4}^{+\cdot}\right)\right]$ complex is then involved in a series of chain reactions $\left(\mathrm{K}_{4}, \mathrm{~K}_{6}, \mathrm{~K}_{\mathrm{dim}}\right)$ driven by the stability of the final product cis-[ $\left[\mathrm{Pd}^{2+}(\mathrm{en})\left(\mathbf{4}^{+}\right)\right]_{\mathrm{Dim}}$, which gets reoxidized at $E_{\mathrm{pa}}=-0.57 \mathrm{~V}$. The irreversible character of the resulting CV curve (dashed line in Figure 5) thus results from a series of $E / C$ reactions proceeding within the time scale of the experiment (a few seconds at $\left.v=0.1 \mathrm{~V} \mathrm{~s}^{-1}\right)^{47}$ and allowing to convert the reduced species cis- $\left[\mathrm{Pd}^{2+}(\mathrm{en})(\mathrm{S})\left(\mathbf{4}^{+*}\right)\right]$ into the folded $\pi$-dimerized complex cis- $\left[\mathrm{Pd}^{2+}(\mathrm{en})\left(\mathbf{4}^{+}\right)\right]_{\text {Dim. }}$. 
The electrochemical behaviour of $4^{2+}$ in the presence of cis$\left[\mathrm{Pd}\left(\mathrm{NO}_{3}\right)_{2}(\mathrm{en})\right]$ at different ligand/metal ratios is summarized in Figure 7 as simple square schemes overlaid on the CV curves. As observed in dynamic combinatorial chemistry, the composition of the mixture is here determined by the thermodynamic stability of each members of the library involving the free ligand $4^{2+}$, the palladium ethylene diamine precursor and the electrons as key components of the selection process leading to the same intramolecular $\pi$-dimer, regardless the $M / L$ ratio in solution.
A 2:1 L/M ratio

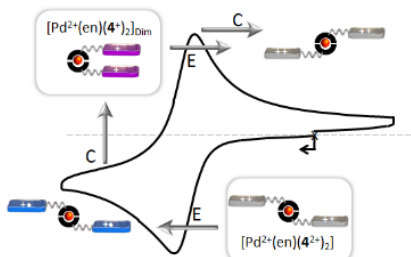

B $1: 3$ L/M ratio

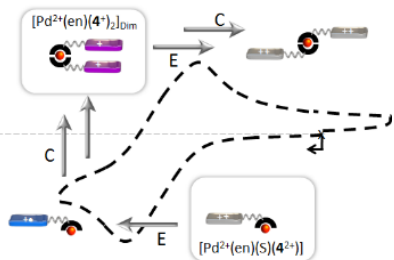

Figure 7. Electrochemical data, and associated chemical steps, recorded for mixture of $4^{2+}$ and cis-[Pd( $\left.\left(\mathrm{NO}_{3}\right)_{2}(\mathrm{en})\right]$ at A) 2:1 and $\left.\mathrm{B}\right)$ 1:3 L:M ratios.

The same investigation was then conducted using a transprotected $\mathrm{PdCl}_{2}$ complex, noted trans- $\left[\mathrm{Pd}\left(\mathrm{Cl}_{2}\left(\mathrm{CH}_{3} \mathrm{CN}\right)_{2}\right]\right.$, as the metal source. The electrochemical data recorded during the progressive addition of palladium to an electrolytic solution of $4^{2+}$ in DMF can be summarized as follow: Addition of 0 to 0.5 molar equivalent of trans-[Pd(Cl) $\left.)_{2}\left(\mathrm{CH}_{3} \mathrm{CN}\right)_{2}\right]$ led to the disappearance of the initial reduction wave (bold solid line in Figure 5B, $E_{1 / 2}{ }^{1}=-0.65$ $\mathrm{mV}, \Delta E_{\mathrm{p}}{ }^{1}=60 \mathrm{mV}, v=0.1 \mathrm{~V} \mathrm{~s}^{-1}$ ) at the expense of a new wave growing at a less negative potential value and featuring a $\Delta E_{\mathrm{p}}$ value of about $37 \mathrm{mV}$ (thin solid line in Figure $5, E_{1 / 2}{ }^{1}=-0.59 \mathrm{~V}, \mathrm{~V}$ $=0.1 \mathrm{~V} \mathrm{~s}^{-1}$ ). Addition of an excess metal then led to a conversion of the latter signal into a fully irreversible wave centered at $E_{\mathrm{pc}}=-$ $0.709 \mathrm{~V}$ (dashed line in Figure 5B).

The task of interpreting these CV curves has also been achieved starting from the NMR data discussed above demonstrating that the mixture obtained after addition of 0.5 molar equivalent of $\mathrm{PdCl}_{2}$ contains the free ligand $4^{2+}$, the $1: 2(\mathrm{M}: \mathrm{L})$ complex trans- $\left[\mathrm{Pd}(\mathrm{Cl})_{2}\left(4^{2+}\right)_{2}\right]$ and the 2:1 (M:L) species trans$\left[\mathrm{Pd}(\mathrm{Cl})_{2} \mathrm{~L}\left(4^{2+}\right)\right]$ in a $3 / 12 / 5$ ratio respectively. From an electrochemical point of view, a simple comparison of the solid curves depicted in Figure $5 \mathrm{~A}$ and $\mathrm{B}$ readily reveals that the reduction potentials of the species formed at this $\mathrm{L}: \mathrm{M}$ ratio with trans- $\left[\mathrm{Pd}(\mathrm{Cl})_{2}\left(\mathrm{CH}_{3} \mathrm{CN}\right)_{2}\right]$ or cis- $\left[\mathrm{Pd}\left(\mathrm{NO}_{3}\right)_{2}\right.$ (en) $]$ are identical. In both cases, the wave developing at a much less negative potential and featuring the same diagnostic $\Delta E_{\mathrm{p}}$ value $(<40 \mathrm{mV})$ is thus attributed to a large scale dynamic reorganisation of the reactants driven by the stabilization of the electrogenerated viologen radicals in the intramolecular $\pi$-dimers $\operatorname{cis}-\left[\mathrm{Pd}^{2+}(\mathrm{en})\left(\mathbf{4}^{+}\right)\right]_{\operatorname{Dim}}$ or trans- $\left[\mathrm{Pd}(\mathrm{Cl})_{2}\left(4^{+}\right)_{2}\right]_{\text {Dim. }}$. The mechanism proposed to generate the latter species from a $1 / 2$ trans- $\left[\mathrm{Pd}\left(\mathrm{Cl}_{2}\left(\mathrm{CH}_{3} \mathrm{CN}\right)_{2} / 4^{2+}\right.\right.$ mixture is summarized in Figure 8 with simple sketches.

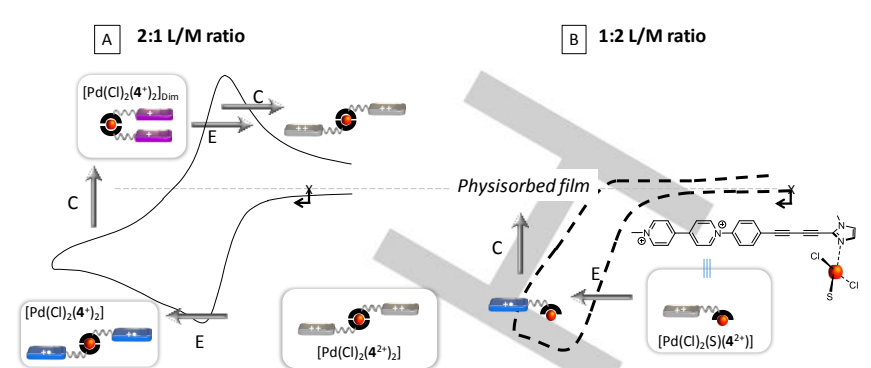

Figure 8. Electrochemical data, and associated chemical steps, recorded for mixtures of $\mathbf{4}^{2+}$ and trans- $\left[\mathrm{Pd}(\mathrm{Cl})_{2}\left(\mathrm{CH}_{3} \mathrm{CN}\right)_{2}\right]$ in $\left.\mathrm{A}\right)$ a $1: 2$ and $\left.\mathrm{B}\right)$ a $2: 1 \mathrm{M} / \mathrm{L}$ ratios.

The exact mechanism remains to be established but the shape of the CV curve indicates that the kinetics of the coupled chemical process is fast compared to the time scale of the CV experiment. As observed with the cis protected palladium precursor, the shape of the CV curve depicted in Figure $8 \mathrm{~A}$ results from a series of fast reactions drawn by the thermodynamic stability of an intramolecular dimer.

A careful examination of the electrochemical data recorded after addition of an excess metal also provided evidence of electron transfer centered on the 1:1 complex trans- $\left[\mathrm{Pd}(\mathrm{Cl})_{2}(\mathrm{~S})\left(\mathbf{4}^{2+}\right)\right]$ seen as the main irreversible signal at $E_{\mathrm{p}}=-0.71 \mathrm{~V}$ in Figure $8 \mathrm{~B}$. As seen with the cis-protected analog, the viologen unit in trans$\left[\mathrm{Pd}(\mathrm{Cl})_{2}(\mathrm{~S})\left(4^{2+}\right)\right]$ gets reduced at about the same potential than the free ligand $\left(E_{\mathrm{p}}=-0.68 \mathrm{~V}\right)$ (Figure $5 \mathrm{~B}$ ). Another intriguing feature of the wave observed only at large $M: L$ ratio with $\mathrm{PdCl}_{2}$ is the apparent/irreversible character of the viologen-based reduction wave. Further investigations carried out in the presence of an excess metal allowed us to attribute this irreversibility to the physisorption of the electrogenerated reduced species on the electrode surface, as revealed by the observation of thick films covering the electrode surface during bulk electrolyses.

\section{Spectro-electrochemical studies}

The existence of a $\pi$-dimerization process coupled to electron transfers centered on the viologen units was further confirmed by spectroelectrochemistry (SEC), which involved regularly recording absorption spectra over time during the potentiostatic reduction of solutions obtained at different $M / L$ ratio. The bulk electrolysis (1e/viologen) of $4^{2+}$ carried out in DMF $(0.4 \mathrm{mM})$ at a platinum electrode led to development of three main bands in the visible range, at $\lambda_{\max }=449 \mathrm{~nm}\left(\varepsilon=44700 \mathrm{~L} \mathrm{~mol}^{-1} \mathrm{~cm}^{-1}\right), 673 \mathrm{~nm}$ $\left(\varepsilon=28100 \mathrm{~L} \mathrm{~mol}^{-1} \mathrm{~cm}^{-1}\right)$ and $722 \mathrm{~nm}\left(\varepsilon=24500 \mathrm{~L} \mathrm{~mol}^{-1} \mathrm{~cm}^{-1}\right)$, attributed to the "free" viologen cation radical in $4^{+}$, which indicates that this radical does not dimerize in these experimental conditions (temperature, solvent and concentration)(Fig. ESI 23).

The evolution of the UV/Vis spectra recorded during the electrolysis of $4^{2+}$ carried out in the presence of 0.5 molar equivalent of cis- $\left[\mathrm{Pd}\left(\mathrm{NO}_{3}\right)_{2}(\mathrm{en})\right]$ or trans- $\left[\mathrm{Pd}(\mathrm{Cl})_{2}\left(\mathrm{CH}_{3} \mathrm{CN}\right)_{2}\right]$ are shown in Figure $9 \mathrm{~A}$ and $\mathrm{B}$, respectively. What strikes at first sight, is the perfect matching found between these two data sets with intense absorption bands progressively growing at $443 \mathrm{~nm}(\varepsilon=$ $\left.29300 \mathrm{~L} \mathrm{~mol}^{-1} \mathrm{~cm}^{-1}\right), 624 \mathrm{~nm}\left(\varepsilon=20000 \mathrm{~L} \mathrm{~mol}^{-1} \mathrm{~cm}^{-1}\right)$ and $960 \mathrm{~nm}$ $\left(\varepsilon=2900 \mathrm{~L} \mathrm{~mol}^{-1} \mathrm{~cm}^{-1}\right)$ for cis-[Pd(NO$\left.)_{2}(\mathrm{en})\right]$ and at $442 \mathrm{~nm}(\varepsilon=$ $\left.27600 \mathrm{~L} \mathrm{~mol}^{-1} \mathrm{~cm}^{-1}\right), 616 \mathrm{~nm}\left(\varepsilon=18200 \mathrm{~L} \mathrm{~mol}^{-1} \mathrm{~cm}^{-1}\right)$ and around $960 \mathrm{~nm}\left(\varepsilon=2300 \mathrm{~L} \mathrm{~mol}^{-1} \mathrm{~cm}^{-1}\right)$ for trans-[Pd(Cl $\left.)_{2}\left(\mathrm{CH}_{3} \mathrm{CN}\right)_{2}\right]$. Another key feature supporting the conclusion that the electro- 
generated cation radicals are involved in both cases in a palladium-assisted $\pi$-dimerization is the observation of the same broad absorption band centered at $960 \mathrm{~nm}$. It is also clear from these SEC curves that the electro-generated dimer is in equilibrium with a non-associated bis radical whose presence in both cased is revealed by the shoulder at $700 \mathrm{~nm}^{48}$

The SEC data discussed above are thus in good agreement with the mechanism proposed in Figure 7 and Figure 8 on the ground of $\mathrm{CV}$ analyses They reveal the formation of the same $\pi$-dimer complex as the main product of the bulk electrochemical reduction of $2 / 1$ mixtures of $4^{2+}$ and cis-[ $\left.\mathrm{Pd}\left(\mathrm{NO}_{3}\right)_{2}(\mathrm{en})\right]$ or trans$\left[\mathrm{Pd}(\mathrm{Cl})_{2}\left(\mathrm{CH}_{3} \mathrm{CN}\right)_{2}\right]$. The data collected at the end of the electrolysis not only feature the same $\lambda_{\max }$ values but also the same distribution between the associated and non-associated forms. In both cases, the $\pi$-dimerized species is the minimum of potential energy pulling all the chemical and electrochemical equilibria involved in solution.

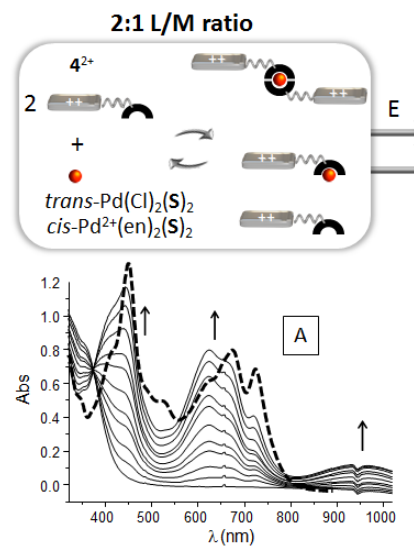

Folded $\pi$-dimer $\quad$ Open bis-radical

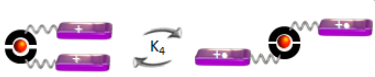

trans- $\left[\mathrm{Pd}(\mathrm{Cl})_{2}\left(\mathbf{4}^{+}\right)_{2}\right]_{\text {Dim }}$ trans- $\left[\mathrm{Pd}(\mathrm{Cl})_{2}\left(\mathbf{4}^{+\bullet}\right)_{2}\right]$

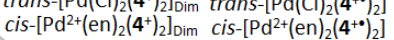

Figure 9. Superposition of UV/Vis absorption spectrum of $\mathbf{4}^{+\cdot}$ (dashed line) and spectra recorded during the exhaustive reduction (one electron per viologen) of $4^{2+}$ in presence of 0.5 molar equivalent of $\mathrm{A}$ ) cis-[Pd( $\left.\left.\mathrm{NO}_{3}\right)_{2}(\mathrm{en})\right]$ (full line) and B) trans-[Pd(Cl $\left.)_{2}\left(\mathrm{CH}_{3} \mathrm{CN}\right)_{2}\right]$ (full line) (DMF + 0.1 M TBAP, $0.4 \mathrm{mM}, 15 \mathrm{~mL}, E_{\text {app }}$ $=-0.8 \mathrm{~V}, \mathrm{I}=1 \mathrm{~mm}, \mathrm{t} \approx 30 \mathrm{~min}$, working electrode $=\mathrm{Pt}$ ).

Similar SEC analyses have then been conducted on a mixture containing the free ligand and an excess of cis- $\left[\mathrm{Pd}\left(\mathrm{NO}_{3}\right)_{2}(\mathrm{en})\right](4$ molar equivalents). This experiment revealed that the UV/Vis absorption spectrum recorded after bulk reduction at $E_{\text {app }}=-0.8 \mathrm{~V}$ (1e/viologen) (Fig. ESI 25) is the exact reproduction of that obtained in the same conditions in the presence of only 0.5 molar equivalent of metal, regardless of the cis- or trans- protected coordination scheme around $\mathrm{Pd}^{2+}\left(\operatorname{cis}-\left[\mathrm{Pd}\left(\mathrm{NO}_{3}\right)_{2}(\mathrm{en})\right]\right.$ or trans$\left[\mathrm{Pd}(\mathrm{Cl})_{2}\left(\mathrm{CH}_{3} \mathrm{CN}\right)_{2}\right]$.) These results are thus consistent with the idea that the one electron reduction of the viologen units leads to the formation of the same $\pi$-dimerized structures, whatever the metal source and whatever the relative ratio between metal and ligand initially introduced in solution. It also serves to confirm the general mechanism developed on the ground of voltammetric data, and more particularly the rearrangements of cis$\left[\mathrm{Pd}^{2+}(\mathrm{en})(\mathrm{S})\left(\mathbf{4}^{2+}\right)\right] \rightarrow$ cis- $\left[\mathrm{Pd}^{2+}(\mathrm{en})\left(\mathbf{4}^{+}\right)_{2}\right]_{\mathrm{Dim}}$ and trans$\left[\mathrm{Pd}(\mathrm{Cl})_{2}(\mathrm{~S})\left(4^{2+}\right)\right] \rightarrow$ trans- $\left[\mathrm{Pd}(\mathrm{Cl})_{2}\left(\mathbf{4}^{+}\right)_{2}\right]_{\text {Dim }}$ triggered by electron transfer. In agreement with the CV data discussed in the previous section, we also found that the exhaustive reduction of $4^{2+}$ performed in the presence of an excess of trans$\left[\mathrm{Pd}(\mathrm{Cl})_{2}\left(\mathrm{CH}_{3} \mathrm{CN}\right)_{2}\right]$ leads to the adsorption of the reduction product on the surface of the electrode, the latter process being easily revealed by a coloring of the electrode

Insights into the structure of trans- $\left[\mathrm{Pd}(\mathrm{Cl})_{2}\left(\mathbf{4}^{+}\right)_{2}\right]_{\text {Dim }}$ and cis$\left[\mathrm{Pd}^{2+}(\mathrm{en})\left(\mathbf{4}^{+}\right)\right]_{\mathrm{Dim}}$ have been provided both by experimental and computational studies. The striking similarity between the spectroscopic signatures recorded after bulk reduction of the free ligand in the presence of the trans- or the cis-protected palladium precursor is the first direct evidence supporting the conclusion that the cofacial arrangement of the viologen radicals in both dimerized species is the same. Use of simple molecular models however suggests that a fully eclipsed stacking of both viologen radicals can only be achieved with the cis-protected metal center (A) as opposed to the partially overlapped staggered conformations (B) systematically obtained with $\mathrm{PdCl}_{2}$ as the result of the geometric and structural constraints imposed by the transprotected square planar arrangement and by the rigidity of the ligand.

DFT investigations have been carried out to confirm these initial findings. The optimized structures of the $\pi$-dimerized complexes cis- $\left[\mathrm{Pd}^{2+}(\mathrm{en})\left(\mathbf{4}^{+}\right)_{2}\right]_{\text {Dim }}$ and trans- $\left[\mathrm{Pd}(\mathrm{Cl})_{2}\left(\mathbf{4}^{+}\right)_{2}\right]_{\text {Dim }}$ obtained at the BP86/6-31G* ${ }^{*}$ LANL2DZ level of theory are depicted in Figure $10 \quad(C, D)$. The structure of cis[Pd2+(en)(4+)]Dim shows the expected cofacial arrangement of the viologen units with an inter-planar sub van der Waals distance of about $3.2 \AA$ (Figure 10C). The structure calculated for trans$[\mathrm{Pd}(\mathrm{Cl}) 2(4+) 2]$ Dim conversely exhibits a staggered conformation wherein both rigid arms intersect over one of the pyridinium rings with an opening angle of $17^{\circ}$ (Figure 10). The large structural differences imposed by the cis- $v s$ trans-protected square planar coordination sphere around the Pd center are thus expected to yield major differences in the spectroscopic signatures of the dimerized species cis- $\left[\mathrm{Pd}^{2+}(\mathrm{en})\left(\mathbf{4}^{+}\right)\right]_{\text {Dim }}$ and trans- $\left[\mathrm{Pd}(\mathrm{Cl})_{2}\left(\mathbf{4}^{+}\right)_{2}\right]_{\text {Dim }}$ (vide supra).The experimental and computational data collected with trans and cis protected metal centers are thus only compatible with a trans $\rightarrow$ cis isomerization of the $\mathrm{PdCl}_{2}$ center triggered by the reduction/dimerization of the viologen centers (trans- $\left[\mathrm{Pd}(\mathrm{Cl})_{2}\left(\mathbf{4}^{+}\right)_{2}\right]_{\mathrm{Dim}} \rightarrow$ cis- $\left.\left[\mathrm{Pd}(\mathrm{Cl})_{2}\left(\mathbf{4}^{+}\right)_{2}\right]_{\mathrm{Dim}}\right)$. This key conclusion is moreover further substantiated by a quite abundant literature showing that cis/trans isomerizations are frequently raised in palladium-based coupling processes or in many other reactions involving $\mathrm{PdCl}_{2}$ moities ${ }^{49-53}$
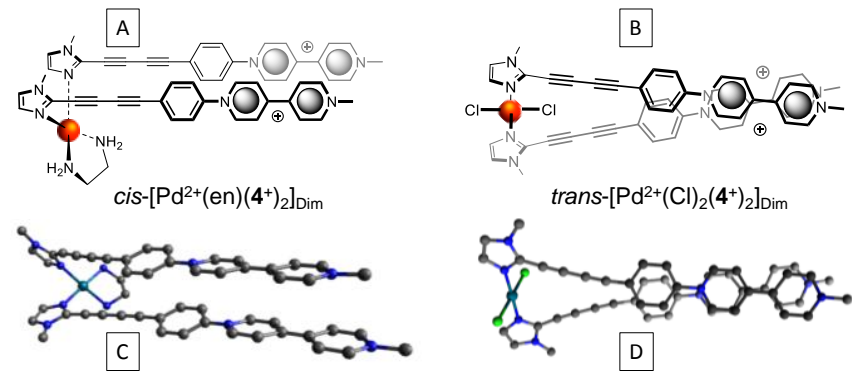

Figure 10. 2D representations $(A, B)$ and optimized structures $(C, D)$ of cis$\left[\mathrm{Pd}^{2+}(\mathrm{en})\left(4^{+}\right)\right]_{\text {Dim }}$ and trans- $\left[\mathrm{Pd}(\mathrm{Cl})_{2}\left(4^{+}\right)_{2}\right]_{\text {Dim }}$ calculated at the BP86/6$31 G^{*}+$ LANL2DZ level of theory.

\section{Conclusions}


We have developed a dynamic supramolecular strategy to promote the $\pi$-dimerization of viologen-based tectons at room temperature and in standard concentration ranges. On the ground of detailed spectroscopic and electrochemical data supported by computational calculations, we have indeed established that palladium centers can be used as inorganic hinges promoting the intramolecular $\pi$-dimerization of two imidazole-appended viologen radicals.

We also found that a one electron reduction of the viologen units in different dynamic metal:ligand mixtures leads to the formation of the same intramolecular $\pi$-dimer, regardless of the initial environment around the metallic precursor (cis- vs transprotected) and of the relative ratio between metal and ligand initially introduced in solution. In line with this finding, our experimental and computational studies carried out with a transprotected metal source revealed the existence of a trans $\rightarrow$ cis isomerization of the coordinated ligands triggered by electron transfer centered on the viologen units. When using trans- $\mathrm{PdCl}_{2}$ as the palladium source, the electron transfer centered on the viologens thus leads to a large scale reorganization of the building blocks involving drastic changes in the stoichiometry and stereochemistry of the palladium/viologen complexes.

We believe that these dynamic combinatorial chemistry-like behaviour involving easy to make building blocks will be a great source of inspiration for the future development of redoxresponsive supramolecular assemblies involving $\pi$-dimerization as actuation forces.

\section{Experimental Section}

Detailled synthetic procedures and characterisation data including additional CV curves and ${ }^{1} \mathrm{H}$ NMR spectra are provided as supporting Information.

\section{Acknowledgements}

This work was supported by the "Agence National de la Recherche" (ANR-12-BS07-0014-01) and by the Labex Arcane (ANR-11-LABX0003-01). Calculations have been performed using the local HPC resources of PSMN (ENS Lyon). CB wishes to thank the ANR (ANR12-BS07-0014-01) and the LABEX iMUST (ANR-10-LABX-0064) of the Université de Lyon, within the program "Investissements d'Avenir" (ANR-11-IDEX-0007).

Keywords: $\pi$-dimer, Viologen, Palladium(II), Metamorphism, Redox-responsive assembly.

\section{References}

[1] R. G. Hicks, Org. Biomol. Chem. 2007, 5, 1321-1338.

[2] A. Heckmann and C. Lambert, Angew. Chem., Int. Ed. Engl. 2012, 51, $326-392$.

[3] N. M. Gallagher, A. Olankitwanit and A. Rajca, J. Org. Chem. 2015, 80, 1291-1298.
[4] M. Mas-Torrent, N. Crivillers, C. Rovira and J. Veciana, Chem. Rev. 2012, 112, 2506-2527.

[5] Y. Wang, M. Frasconi and J. F. Stoddart, ACS Cent. Sci. 2017, 3, 927935.

[6] T. Fukino, H. Yamagishi and T. Aida, Adv. Mater. 2016, 29, 1603888.

[7] A. C. Fahrenbach, C. J. Bruns, H. Li , A. Trabolsi, A. Coskun and J. F. Stoddart, Acc. Chem. Res. 2014, 47, 482-493.

[8] S. V. Rosokha and J. K. Kochi, Acc. Chem. Res. 2008, 41, 641-653.

[9] A. C. Fahrenbach, S. C. Warren, J. T. Incorvati, A.-J. Avestro, J. C. Barnes, J. F. Stoddart and B. A. Grzybowski, Adv. Mater. 2013, 25, 331 348.

[10] Y. H. Ko, E. Kim, I. Hwang and K. Kim, Chem. Commun. 2007, 13051315.

[11] J.-M. Lu, S. V. Rosokha and J. K. Kochi, J. Am. Chem. Soc. 2003, 125, 12161-12171.

[12] T. Nishinaga and K. Komatsu, Org. Biomol. Chem. 2005, 3, 561-569.

[13] J. M. Spruell, Pure Appl. Chem. 2010, 82, 2281-2294.

[14] D.-W. Zhang, J. Tian, L. Chen, L. Zhang and Z.-T. Li, Chem. Asian J. 2015, 10, 56-58

[15] C. Kahlfuss, E. Saint-Aman and C. Bucher, in Organic Redox Systems: Synthesis, Properties, and Applications, ed. T. Nishinaga, John Wiley and sons, New-York, 2016, pp. 39-88.

[16] P. M. S. Monk, N. M. Hodgkinson and S. A. Ramzan, Dyes and Pigments 1999, 43, 207-217.

[17] M. R. Geraskina, A. S. Dutton, M. J. Juetten, S. A. Wood and A. H. Winter, Angew. Chem., Int. Ed. Engl. 2017, 129, 9563-9567.

[18] C. M. Ronconi, J. F. Stoddart, V. Balzani, M. Baroncini, P. Ceroni, C. Giansante and M. Venturi, Chem. Eur. J. 2008, 14, 8365-8373.

[19] F. Marchioni, M. Venturi, P. Ceroni, V. Balzani, M. Belohradsky, A. M. Elizarov, H.-R. Tseng and J. F. Stoddart, Chem. Eur. J. 2004, 10, 63616368.

[20] J. W. Lee, S. Samal, N. Salvapalam, H.-J. Kim and K. Kim, Acc. Chem. Res. 2003, 36.

[21] Y. H. Ko, E. Kim, I. Hwang and K. Kim, Chem. Commun. 2007, 13051315.

[22] P. A. Quintela, A. Diaz and A. E. Kaifer, Langmuir 1988, 4, 663-667.

[23] H. D. Correia, S. Chowdhury, A. P. Ramos, L. Guy, G. J.-F. Demets and C. Bucher, Polym. Int 2018, DOI: 10.1002/pi.5709, Accepted Manuscript.

[24] M. Marchini, M. Baroncini, G. Bergamini, P. Ceroni, M. D'Angelantonio, P. Franchi, M. Lucarini, F. Negri, T. Szreder and M. Venturi, Chem. Eur. J. 2017, 23, 6380-6390.

[25] R. Kannappan, C. Bucher, E. Saint-Aman, J.-C. Moutet, A. Milet, M. Oltean, E. Métay, S. Pellet-Rostaing, M. Lemaire and C. Chaix, New J. Chem. 2010, 34, 1373-1386.

[26] C. Kahlfuss, A. Milet, J. A. Wytko, J. Weiss, E. Saint-Aman and C. Bucher, Org. Lett. 2015, 17, 4058-4061.

[27] C. Kahlfuss, E. Métay, M.-C. Duclos, M. Lemaire, M. Oltean, A. Milet, E. Saint-Aman and C. Bucher, C. R. Chimie 2014, 17, 505-511.

[28] C. Kahlfuss, E. Métay, M.-C. Duclos, M. Lemaire, A. Milet, E. Saint-Aman and C. Bucher, Chem. Eur. J. 2014, 21, $2090-2106$.

[29] C. Kahlfuss, S. Denis-Quanquin, N. Calin, E. Dumont, M. Garavelli, G. Royal, S. Cobo, E. Saint-Aman and C. Bucher, J. Am. Chem. Soc. 2016 , 138, 15234-15242.

[30] A. lordache, M. Retegan, F. Thomas, G. Royal, E. Saint-Aman and C Bucher, Chem. Eur. J. 2012, 18, 7648-7653.

[31] A. lordache, M. Oltean, A. Milet, F. Thomas, E. Saint-Aman and C Bucher, J. Am. Chem. Soc. 2012, 134, 2653-2671.

[32] A. lordache, R. Kanappan, E. Métay, M.-C. Duclos, S. Pellet-Rostaing, M. Lemaire, A. Milet, E. Saint-Aman and C. Bucher, Org. Biomol. Chem. 2013, 11, 4383-4389.

[33] W. S. Abdul-Hassan, D. Roux, C. Bucher, S. Cobo, F. Molton, E. SaintAman and G. Royal, Chemistry - A European Journal 2018, 24, 1296112969. 
[34] C. Kahlfuss, T. Gibaud, S. Denis-Quanquin, S. Chowdhury, G. Royal, F. Chevallier, E. Saint-Aman and C. Bucher, Chem. Eur. J. 2018, 24 13009-13019.

[35] Z. Huo, A. Bonnefont, Y. Liang, R. Farha, M. Goldmann, E. Saint-Aman, H. Xu, C. Bucher and L. Ruhlmann, Electrochim. Acta 2018, 274, 177 191.

[36] Z. Huo, J.-P. Gisselbrecht, R. Farha, M. Goldmann, E. Saint-Aman, C. Bucher and L. Ruhlmann, Electrochim. Acta 2014, 122, 108- 117.

[37] M. Marchini, M. Baroncini, G. Bergamini, P. Ceroni, M. D'Angelantonio, P. Franchi, M. Lucarini, F. Negri, T. Szreder and M. Venturi, Chem. Eur. J. 2017, 23, 6380-6390.

[38] K. Nchimi-Nono, P. Dalvand, K. Wadhwa, S. Nuryyeva, S. Alneyadi, T. Prakasam, A. C. Fahrenbach, J.-C. Olsen, Z. Asfari, C. Platas-Iglesias, M. Elhabiri and A. Trabolsi, Chem. Eur. J. 2014, 20, 7334-7444.

[39] L. Chen, H. Wang, D.-W. Zhang, Y. Zhou and Z.-T. Li, Angew. Chem., Int. Ed. Engl. 2015, 54, 4028-4031.

[40] C. Gao, S. Silvi, X. Ma, H. Tian, A. Credi and M. Venturi, Chem. Eur. J. 2012, 18, 16911-16921.

[41] E. Masson, X. Ling, R. Joseph, L. Kyeremeh-Mensah and X. Lu, RSC Adv. 2012, 2, 1213-1247.

[42] N. B. Debata, D. Tripathy and D. K. Chand, Coord. Chem. Rev. 2012, 256, 1831-1945.

[43] C. C. C. Johansson Seechurn, M. O. Kitching, T. J. Colacot and V. Snieckus, Angew. Chem., Int. Ed. Engl. 2012, 51, 5062-5085.

[44] W.-C. Cheng and M. J. Kurth, Org. Prep. Proced. Int. 2002, 34, 585-585.

[45] J. D. Crowley, I. M. Steele and B. Bosnich, Chem. Eur. J. 2006, 12, 8935 $-8951$.
[46] The effectiveness of the dimerization process (equilibrium characterized by $\mathrm{K}_{\text {dim }}$ ) coupled to the viologen-centered electron transfer leads to a situation in which the second one-electron reduction happens at a less negative potential than the initial one and thus to the existence of a disproportionation equilibria yielding the bis radical from the monoreduced species. These issue have been discussed in detail in reference 25 or 31.

[47] The effect of scan rate on the shape of the CV curves recorded at this $M: L$ ratio can be seen in Figure ESI 31. The complex evolution of the peak to peak potential shift $(\Delta \mathrm{Ep})$ with scan rate, albeit not fully explained,most probably result from the competitive effects of scan rate on the kinetics of the electrochemical $(\mathrm{E})$ and coupled chemical steps (C).

[48] The dimer can hardly be obtained as a "pure" species as it usually exist in equilibrium with the non associated free radical. The UV-Vis absorption spectrum of pure dimers is thus only seldom observed in standard concentration and temperature ranges. A quantitative dimerization has for instance been reported in 2016 (ref 29) in standard conditions with a covalently linked bisviologen allowing to lock the structure of the dimer with additional attractive forces.

[49] A. L. Casado and P. Espinet, Organometallics 1998, 17, 954-959.

[50] J. Dale C. Smith, andGary M. Gray*, Inorg. Chem. 1998, 37, 1791-1797.

[51] J. R. Durig and B. R. Mitchell, Appl. Spectrosc. 1967, 21, 221-224

[52] R. A. Gossage, H. A. Jenkins, N. D. Jones, R. C. Jones and B. F. Yates, Dalton Trans. 2008, 23, 3115-3122.

[53] X.-X. Lu, H.-S. Tang, C.-C. Ko, J. K.-Y. Wong, N. Zhu and V. W.-W. Yam, Chem. Commun. 2005, 1572-1574. 


\section{FULL PAPER}

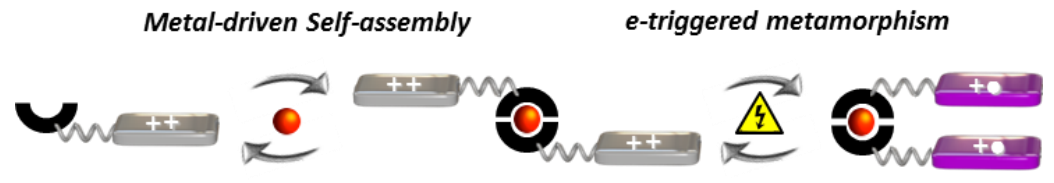

A dynamic supramolecular approach is developed to promote the m-dimerization of viologen radicals at room temperature and in standard concentration ranges. It involves cis- or trans-protected palladium centers serving as inorganic hinges linking two functionalized viologens endowed with metal-ion coordinating properties.
Christophe Kahlfuss, Raymond Grüber, Elise Dumont, Guy Royal, Floris Chevalier, Eric Saint-Aman* and Christophe Bucher*

Page No. - Page No.

Dynamic Molecular

Metamorphism involving

Palladium-Assisted

Dimerization of $\pi$-Cation D.dis1n 